\title{
FASES ESTACIONÁRIAS MODERNAS PARA CROMATOGRAFIA LÍQUIDA DE ALTA EFICIÊNCIA EM FASE REVERSA
}

Liane Maldaner, Carol H. Collins e Isabel C. S. F. Jardim*

Departamento de Química Analítica, Instituto de Química, Universidade Estadual de Campinas, CP 6154, 13083-970 Campinas - SP, Brasil

Recebido em 15/12/09; aceito em 1/4/10; publicado na web em 29/6/10

\begin{abstract}
MODERN STATIONARY PHASES FOR REVERSED PHASE HIGH PERFORMANCE LIQUID CHROMATOGRAPHY. This review first discusses the limitations of many of the supports and stationary phases used in reversed phase high performance liquid chromatography and then describes those, developed more recently, that present better stabilities and more versatile selectivities. Emphases will be given to stationary phases that use higher purity silicas, hybrid silicas, monolithic silicas, metallic oxides and mixed oxides as supports and those that have embedded polar groups or contain phenyl or fluoro groups as the stationary phase as well as the phases used for mixed mode or hydrophilic interaction separations. These modern stationary phases facilitate the analysis of complex mixtures.
\end{abstract}

Keywords: RP-HPLC; modern stationary phases; stability.

\section{INTRODUÇÃO}

O alto nível de desenvolvimento e expansão alcançado pela cromatografia líquida de alta eficiência em fase reversa (CLAE-FR), ao longo das últimas décadas, deve-se principalmente a sua vasta aplicabilidade, que engloba o desenvolvimento de novos produtos, o controle da qualidade desses produtos e, também, as possíveis contaminações provenientes desses produtos e dos disponíveis no mercado há anos. Dentro deste contexto estão envolvidas as indústrias farmacêuticas, alimentícias, agropecuárias e químicas, as agências reguladoras que tratam do meio ambiente e outras. A ampla aplicabilidade da CLAE-FR foi o que impulsionou e continua impulsionando as pesquisas em busca do aprimoramento desta técnica, principalmente referente ao desenvolvimento de novas fases estacionárias (FE). Hoje a CLAE-FR pode ser considerada uma técnica de análise (separação, confirmação e quantificação) bem difundida e empregada, em consequência das colunas cromatográficas e equipamentos de alta tecnologia que se encontram disponíveis.

As FE empregadas em CLAE-FR consistem de uma camada orgânica apolar ligada quimicamente ou imobilizada ou apenas sorvida a um suporte cromatográfico. A forma de obtenção dessas camadas apolares e a variedade de óxidos empregados como suportes cromatográficos resultam nos diferentes tipos de FE. O método mais comum e também o mais empregado para a obtenção das FE consiste na introdução de monocamadas orgânicas através de reações com reagentes apropriados, que dá origem às fases estacionárias quimicamente ligadas (FEQL). ${ }^{1-4}$ As FEQL podem ser obtidas por diferentes processos, como esterificação, cloração seguida por reação com reagente de Grignard ou com compostos organo-lítio e organossilanização. Uma forma alternativa de preparo de FE é o método de recobrimento do suporte com polímeros orgânicos, que pode ser realizado de duas maneiras: mistura de um polímero pré-sintetizado de composição química bem definida em solução com o suporte e posterior evaporação do solvente e, polimerização in situ de uma solução de monômeros ou oligômeros, iniciada ou propagada na superfície do suporte, geralmente seguida de uma etapa de imobilização. ${ }^{4,5}$ Entretanto, dentre as formas de preparo de FE, as FEQL obtidas pelo processo de organossilanização apresentam melhor reprodutibilidade e também melhor estabilidade hidrolítica e, hoje, dominam o preparo das FE comerciais.

\footnotetext{
*e-mail: icsfj@iqm.unicamp.br
}

Atualmente, a ênfase nas pesquisas e nos desenvolvimentos de novas FE para CLAE-FR está voltada para dois pontos principais: a estabilidade e a seletividade das FE, ou seja, o aumento do tempo de vida das FE em condições adversas, principalmente em $\mathrm{pH}$ altos, e o desenvolvimento de FE que possuam características específicas para um composto ou para uma classe de compostos, respectivamente. Associado a esses dois pontos principais está a busca por melhorias na repetibilidade de coluna para coluna e de lote para lote, na simetria de pico para compostos básicos e no desenvolvimento de materiais aptos para serem empregados em análises rápidas e em temperaturas mais elevadas. ${ }^{6}$

Muitas FE novas emergiram a partir das pesquisas direcionadas à produção de materiais mais estáveis, compreendendo e minimizando as interações silanol-analito, e abordando a necessidade para separações mais seletivas. Estas FE emergentes foram designadas de fases estacionárias modernas e serão descritas a seguir.

\section{AVANÇOS NA ESTABILIDADE DAS FASES ESTACIONÁRIAS MODERNAS}

\section{Novos suportes cromatográficos}

São muitas as características requeridas para que um suporte cromatográfico seja considerado ideal para ser empregado no preparo de FE. Segundo Unger e Trudinger, ${ }^{7}$ estas características são: o método de síntese das partículas deve ser altamente reprodutível; as partículas devem ter uma faixa estreita de distribuição de tamanho e alta área superficial; os poros devem ter um diâmetro apropriado para o tamanho do analito e boa conectividade para permitir uma alta taxa de transferência de massa; deve resistir térmica, mecânica e quimicamente à degradação; possuir uma superfície que seja tanto energeticamente homogênea quanto quimicamente modificável e exibir o mínimo de intumescimento, no caso das FE poliméricas ou das FE preparadas por recobrimento polimérico.

Em vista das características citadas, a sílica continua sendo o material cromatográfico mais empregado e também o mais promissor para o desenvolvimento de novas FE. Entretanto, o uso da sílica como suporte cromatográfico "ideal" fica limitado em dois aspectos principais, a estabilidade química e térmica ${ }^{8}{ }^{814}$ A estabilidade química das FE baseadas em sílica é limitada ao uso de fases móveis (FM) com $\mathrm{pH}$ na faixa de 2 a 8 . Em pH acima de 8 ocorre a dissolução da sílica e o colapso da FE e, em pH menores que 2, ocorre a hidrólise 
da ligação siloxano (Si-O-Si-C), ou seja, ocorre a quebra da ligação entre a fase ligada e o suporte cromatográfico, resultando em uma perda contínua de fase ligada, com subsequente perda de retenção do analito. A estabilidade térmica é limitada ao uso de temperaturas elevadas (acima de $60{ }^{\circ} \mathrm{C}$ ) associado ao uso de alta porcentagem de solvente aquoso na composição da FM, uma vez que nestas condições a sílica começa a solubilizar, ocorrendo o eventual colapso do leito cromatográfico, com consequente diminuição dos tempos de retenção dos analitos, e o tempo de vida da coluna é reduzido significativamente. ${ }^{6}$

Dessa forma, estas limitações encorajam o desenvolvimento de novos suportes cromatográficos e modificações do suporte de sílica e/ou das FE. Dentre os desenvolvimentos recentes podem ser destacados, as partículas de sílica moderna, que englobam as sílicas de alta pureza, as sílicas híbridas, as sílicas monolíticas e as sílicas superficialmente porosas, e os óxidos metálicos e mistos.

\section{Sílica moderna}

A sílica foi o material empregado nas primeiras separações cromatográficas e evoluiu ao longo dos anos, devido as suas propriedades favoráveis, e hoje, com características muito mais avançadas, continua sendo o material cromatográfico mais apropriado para as separações cromatográficas.

No início da cromatografia líquida pressurizada, por volta dos anos $60,,^{15-17}$ eram empregadas partículas de sílica porosa de forma irregular e com grande distribuição de tamanho, na faixa de 40-50 $\mu \mathrm{m}$, com as quais se realizava a cromatografia em fase normal (FN). A forma de obtenção dessas partículas era basicamente a moagem de partículas maiores como, por exemplo, grumos de xerogel, e posterior classificação por tamanho com o uso de peneiras com abertura regulável. Essas partículas irregulares de diâmetro grande evoluíram para partículas menores, na faixa de tamanho de $30-40 \mu \mathrm{m}$, que ainda hoje são empregadas em cromatografia líquida clássica (CLC), depois para partículas na faixa de tamanho de $15-20 \mu \mathrm{m}$ e de $10-3 \mu \mathrm{m}$, preparadas pela precipitação da sílica gel de uma solução de silicato, seguida por secagem, moagem e separação de tamanho por decantação.

Na segunda metade da década de $60,{ }^{15,17}$ foram desenvolvidas as partículas de sílica superficialmente porosas, designadas de partículas peliculares, com o intuito de reduzir a dispersão da banda cromatográfica. Estas partículas, de aproximadamente $40 \mu \mathrm{m}$, eram compostas de um núcleo sólido de pérola de vidro revestido com uma camada de $1 \mu \mathrm{m}$ de sílica porosa, que foram comercializadas pela DuPont Company com o nome de Zipax e pela Waters Corporation com o nome de Corasil. Estas partículas foram empregadas em colunas de 50 e $100 \mathrm{~cm}$ para separações em fase normal e em fase reversa (FR); esta última, inicialmente com uma camada de líquido adsorvido e na década de 70 com silanos ligados covalentemente.

Estas partículas caíram em desuso em CLAE devido ao surgimento das partículas esféricas porosas de 10 e de $5 \mu \mathrm{m}$, na década de 70 e na de 80 , respectivamente. ${ }^{15-19}$ A uniformidade da forma e o tamanho das partículas propiciaram colunas melhores recheadas que resultaram no aumento de eficiência e de resolução. Para a obtenção dessas partículas, diferentes rotas de síntese foram empregadas: dispersões da sílica coloidal e geleificação num sistema de duas fases; hidrólise e policondensação de polietoxissiloxano (PES) em esferas de sílica hidrogel por agitação, em um sistema de duas fases (processo sol-gel); aglutinação de soluções coloidais de sílica na presença de polímero seguido de calcinação das esferas; secagem por vaporização de suspensões coloidais de sílica e, formação e crescimento de nano partículas de sílica em suspensões. Nos dias atuais, a obtenção de partículas esféricas de sílica porosa se dá basicamente por variações no processo sol-gel.
Com o advento das partículas esféricas e porosas, no período de 1970 a 1995, as colunas analíticas recheadas com partículas irregulares foram substituídas por colunas recheadas com partículas esféricas e, a partir daí, a evolução vem ocorrendo no sentido de melhorar estas partículas de sílica para tornar a CLAE uma técnica de separação mais versátil e moderna.

O desenvolvimento de novos suportes cromatográficos de sílica e/ou o aprimoramento desses suportes está voltado para melhorar a estabilidade química e térmica, diminuir a acidez dos grupos silanois superficiais e tornar os materiais aptos para a realização de análises mais rápidas. Dessa forma, podem-se dividir os suportes cromatográficos modernos baseados em sílica em dois segmentos, os que evoluíram para o aumento da estabilidade química e térmica e redução da acidez, a sílica de alta pureza e a sílica híbrida, e os que evoluíram para serem compatíveis com análises mais rápidas, porém mantendo as mesmas características dos anteriores, a sílica superficialmente porosa e a sílica monolítica.

\section{Sílica de alta pureza}

A denominação sílica de alta pureza ou, segundo alguns pesquisadores da área, sílica do tipo B, é empregada para partículas de sílica com baixo teor de metais. ${ }^{18,20}$ A quantidade de traços de metais depende do processo de síntese e do material de partida, mas geralmente a sílica cromatográfica possui em torno de 0,1 a $0,3 \%$ de metais. Dentre os metais comumente encontrados na sílica (Fe, $\mathrm{Al}, \mathrm{Na}, \mathrm{K}, \mathrm{Mg}, \mathrm{Ca}, \mathrm{La}, \mathrm{Ti}, \mathrm{Zr}, \mathrm{Cu}, \mathrm{Cr}, \mathrm{Zn}$ ), a redução do teor de $\mathrm{Al}$ e Fe para quantidades inferiores a $3 \mu \mathrm{g} / \mathrm{g}$ e do teor de $\mathrm{Ti}, \mathrm{Zr}$ e $\mathrm{Zn}$ para quantidades não detectáveis por absorção atômica caracterizam a sílica como sendo de alta pureza. Os tratamentos usados para eliminar as impurezas metálicas após a obtenção das partículas de sílica, preparadas pelo processo sol-gel a partir de tetraetoxissilano (TEOS) previamente destilado, consistem basicamente em processos de lavagens ácidas e de re-hidroxilação da superfície após a desidratação a alta temperatura. ${ }^{18,19,21}$

O grande inconveniente da presença de traços metálicos na sílica cromatográfica é o aumento da acidez dos grupos silanois ( $\mathrm{Si}-\mathrm{OH}$ ) provocado pela proximidade de átomos metálicos. Estima-se que a acidez desses grupos aumenta de tal forma que eles interagem 50 vezes mais fortemente com os compostos em análise que os grupos silanois que não possuem impurezas metálicas em suas adjacências. Dessa forma, podem causar alargamento substancial da banda cromatográfica, principalmente dos compostos básicos, perda de resolução cromatográfica e reações químicas indesejáveis. ${ }^{20}$ Dessa forma, a sílica cromatográfica deve ser de alta pureza para que as separações cromatográficas sejam mais eficientes e seletivas. Baseado nestes conceitos, as partículas de sílica e de sílica híbrida de diferentes tamanhos $(5,3,2,5$ ou $\leq 2 \mu \mathrm{m})$ empregadas como suporte cromatográfico das FE modernas são de alta pureza.

\section{Sílica híbrida}

As partículas de sílica híbrida contêm componentes inorgânicos, como a sílica, e componentes orgânicos, como um organossilano, e reúnem as vantagens de ambos componentes. ${ }^{15,22}$

A síntese das partículas híbridas é realizada por uma reação de silanização, ou seja, pela mistura de dois monômeros altamente puros, na qual um vai gerar unidades de $\mathrm{SiO}_{2}$ durante o processo de síntese e o outro vai formar unidades contendo um organossilano. As partículas resultantes contêm grupos organossilano incorporados na sua estrutura e na sua superfície. Os primeiros processos de síntese de partículas de sílica híbrida resultaram em partículas de sílica com ligações silício-hidrogênio $(\mathrm{Si}-\mathrm{H})$ incorporadas e possuíam 
propriedades cromatográficas únicas, principalmente aumento da estabilidade química e redução das interações indesejáveis com os grupos silanois residuais. ${ }^{22} \mathrm{~A}$ Microsolv ${ }^{\mathrm{TM}}$ emprega estas partículas de sílica híbrida com ligações silício-hidrogênio na fabricação de suas colunas cromatográficas e as denomina de sílica TYPE-C ${ }^{\text {TM }}{ }^{23,24}$

A tecnologia híbrida desenvolvida pela Waters Corporation consiste no uso de silanos com ligações silício-metil ${ }^{15,25}\left(\mathrm{Si}-\mathrm{CH}_{3}\right)$ e com pontes de etano ${ }^{26,27}\left(\mathrm{Si}-\mathrm{CH}_{2}-\mathrm{CH}_{2}-\mathrm{Si}\right.$ ), (Figura 1A) envolvendo o mesmo processo de síntese descrito acima, mais especificamente, a partir da reação de tetraetoxissilano e metiltrietoxissilano e, tetraetoxissilano e bis(trietoxissililetano), respectivamente. As partículas de sílica híbrida com ligações silício-metil foram desenvolvidas em 1999, denominadas de partículas de sílica híbrida de $1^{\text {a }}$ geração e são empregadas nas colunas comercializadas como XTerra ${ }^{\circledR}$. Estas partículas possuem maior resistência mecânica, produzem altas eficiências, possuem estabilidade na faixa de $\mathrm{pH}$ de 1-12 e geram picos simétricos para os compostos básicos. Em 2003, foram introduzidas as partículas de sílica híbrida com pontes de etano, denominadas de partículas de sílica híbrida de $2^{\mathrm{a}}$ geração, que são empregadas nas colunas comercializadas como $\mathrm{XBridge}^{\mathrm{TM}}$. $\mathrm{O}$ desenvolvimento dessas partículas foi direcionado para análises rápidas, sendo que as primeiras partículas fabricadas com essa tecnologia foram de 1,7 $\mu \mathrm{m}$ e próprias para serem usadas na cromatografia líquida de ultra eficiência (CLUE) ${ }^{28}$ Essas partículas $\mathrm{XBridge}^{\mathrm{TM}}$ possuem ainda maior estabilidade mecânica, são resistentes a uma faixa de $\mathrm{pH}$ de 1-12 e fornecem boa simetria de pico e altas eficiências. Além disso, são estáveis em temperaturas mais elevadas, de acordo com o fabricante de até $60{ }^{\circ} \mathrm{C}$, entretanto, já foram publicados trabalhos reportando que estas partículas são estáveis em temperaturas de 100 ${ }^{\circ} \mathrm{C}^{29} \mathrm{e}$ de até $150{ }^{\circ} \mathrm{C} .{ }^{30}$

Recentemente a Phenomenex, ${ }^{31}$ com a tecnologia TWIN ${ }^{\mathrm{TM}}$ (two in one), e a Akzo Nobel, ${ }^{32}$ com a tecnologia Eternity ${ }^{\mathrm{TM}}$, vêm desenvolvendo partículas de sílica com uma camada de um organossilano enxertada na superfície de um núcleo de sílica porosa (Figura 1B). Esse processo é realizado no estágio final da fabricação da sílica e, dessa forma, a partícula mantém a força mecânica e a rigidez da sílica, promovendo altas eficiências, enquanto que a camada de sílica orgânica protege a partícula do ataque químico. Estas partículas são estáveis em uma faixa de $\mathrm{pH}$ de 1-12, possuem tempo de vida mais longo e fornecem boa simetria de pico. Com o mesmo intuito a Selerity Technologies ${ }^{33,34}$ vem desenvolvendo as partículas Blaze ${ }_{200}{ }^{\mathrm{TM}}$, que consistem de partículas de sílica recobertas por um silano polidentado, com múltiplos pontos de ligação com a sílica e com alto grau de entrecruzamento, que conferem a essas partículas alta estabilidade térmica (até $200{ }^{\circ} \mathrm{C}$ ), química (na faixa de $\mathrm{pH}$ de 1-12) e hidrolítica.

\section{Sílica superficialmente porosa}

As partículas superficialmente porosas modernas, denominadas de Fused Core (partículas de núcleo fundido), vêm sendo desenvolvidas baseadas na mesma teoria das partículas peliculares da década de 60. ${ }^{15,35,36}$ Entretanto, hoje estas partículas são constituídas somente de sílica e o processo de fabricação consiste basicamente de duas etapas. $\mathrm{Na}$ primeira, é formado o núcleo sólido através da sinterização de uma partícula de sílica porosa a alta temperatura e, em seguida, esse núcleo sólido é revestido por uma camada de sílica porosa (Figura 2). As principais vantagens apresentadas por estas partículas são a baixa resistência à transferência de massa, permitindo análises rápidas sem gerar altas pressões, alta resistência mecânica, capacidade de amostra competitiva com as partículas totalmente porosas menores que $2 \mu \mathrm{m}$ e eficiências mais altas quando comparadas com partículas porosas de mesmo tamanho. São geralmente empregadas para a separação de macromoléculas como os peptídeos e as proteínas. ${ }^{15,17}$
(A)

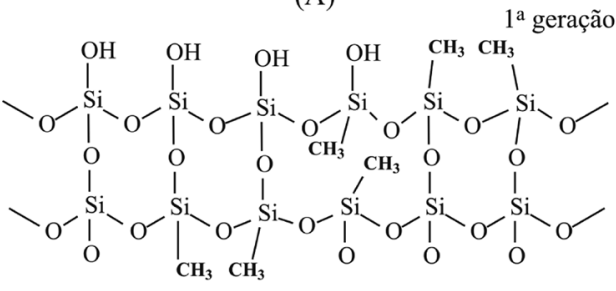

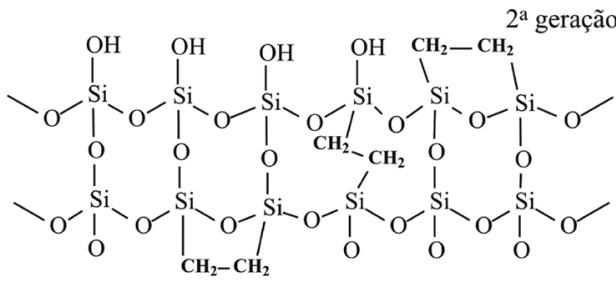

(B)

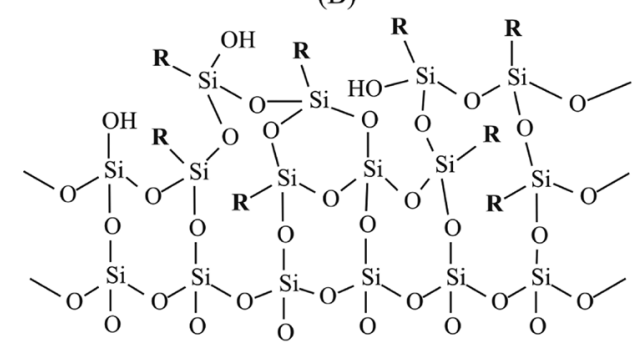

Figura 1. Estruturas das partículas de sílica híbrida: (A) sílica híbrida típica, de $1^{a}$ e $2^{a}$ geração e $(B)$ sílica híbrida com uma camada de um organossilano (R) na superfície

Estas partículas vêm sendo desenvolvidas pela: Agilent Technologies, denominadas de Poroshell, ${ }^{17,37,38}$ com tamanho de 2,7 $\mu \mathrm{m}$ (núcleo sólido de $1,7 \mu \mathrm{m}$ e a camada porosa de $0,5 \mu \mathrm{m}$ ) e de $5 \mu \mathrm{m}$ (núcleo sólido de 4,5 $\mu \mathrm{m}$ e a camada porosa de 0,25 $\mu \mathrm{m}$ ); Advanced Materials Technology, denominadas de Halo ${ }^{\mathrm{TM}},{ }^{15,36,39}$ com tamanho de 2,7 $\mu \mathrm{m}$, similares às Poroshell; Supelco, sendo denominadas de Ascentis ${ }^{\mathrm{TM}} \mathrm{Ex}-$ press, ${ }^{36,40}$ com tamanho de 2,7 $\mu \mathrm{m}$, similares às Poroshell e $\mathrm{Halo}^{\mathrm{TM}} \mathrm{e}$, Phenomenex, denominadas de Kinetex ${ }^{\mathrm{TM}}$ Core-Shell, ${ }^{41}$ com tamanho de 2,6 $\mu \mathrm{m}$ (núcleo sólido de 1,9 $\mu \mathrm{m}$ e a camada porosa de $0,35 \mu \mathrm{m}$ ) e de $1,7 \mu \mathrm{m}$ (núcleo sólido de $1,25 \mu \mathrm{m}$ e a camada porosa de $0,23 \mu \mathrm{m}$ ).
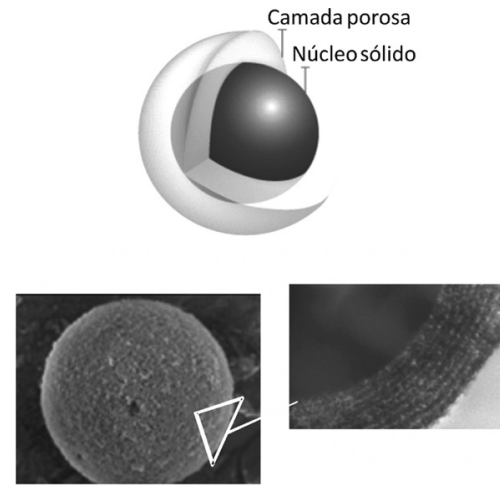

Figura 2. Representação esquemática e micrografia de uma partícula de sílica superficialmente porosa e ampliação da área destacada que corresponde à camada porosa. Adaptada da ref. 4

\section{Sílica monolítica}

A sílica monolítica é um leito contínuo de sílica porosa, ${ }^{15}$ no formato de um bastão ou haste, que contém uma distribuição de tamanho 
de poro bimodal, composta por macro $(\sim 2 \mu \mathrm{m})$ e mesoporos $(\sim 13 \mathrm{~nm})$ (Figura 3). As FE monolíticas são constituídas de sílica monolítica funcionalizada e descritas como um meio contínuo de separação, que possui uma estrutura sólida e altamente porosa que fornecem alta permeabilidade e eficiência de coluna. ${ }^{42} \mathrm{~A}$ alta permeabilidade desses materiais permite o uso de vazões de FM altas, sem aumento da pressão no sistema cromatográfico, resultando em separações rápidas e sem perda de eficiência, devido à alta taxa de transferência de massa, entretanto, esta alta permeabilidade reduz a capacidade de aceitação de amostra pela coluna, ou seja, a quantidade de amostra que pode ser injetada na coluna cromatográfica. A eficiência das colunas monolíticas é comparável às colunas recheadas com partículas porosas de tamanho de $3-5 \mu \mathrm{m}$. . $^{15,18,42-44}$

O preparo da sílica monolítica é realizado pelo processo solgel. ${ }^{15,42,44}$ As etapas comumente envolvidas neste processo são o preparo de uma solução coloidal inicial, a transferência dessa solução para um molde de policarbonato onde ocorrerá a geleificação, o envelhecimento e a secagem do monolito. Após a secagem, é realizado o revestimento do monolito pela transferência do mesmo para um tubo de PEEK (poli(éter-éter-cetona)), que se ajusta ao diâmetro do bastão obtido. A funcionalização do monolito pode ser realizada on column ou antes do revestimento.

As colunas de sílica monolítica disponíveis no mercado são a Chromolith $^{\circledR}$ fabricada pela Merck $^{45}$ e a Onyx ${ }^{\mathrm{TM}}$ fabricada pela Phenomenex, ${ }^{46}$ porém com tecnologia licenciada pela Merck. Em ambas as marcas, encontram-se colunas funcionalizadas com grupos alquila octil (C8) e octadecil (C18), com diferentes especificações de tamanho, inclusive com dimensões adequadas para serem empregadas em cromatografia líquida acoplada à espectrometria de massas (CL-EM). ${ }^{35,45,46}$

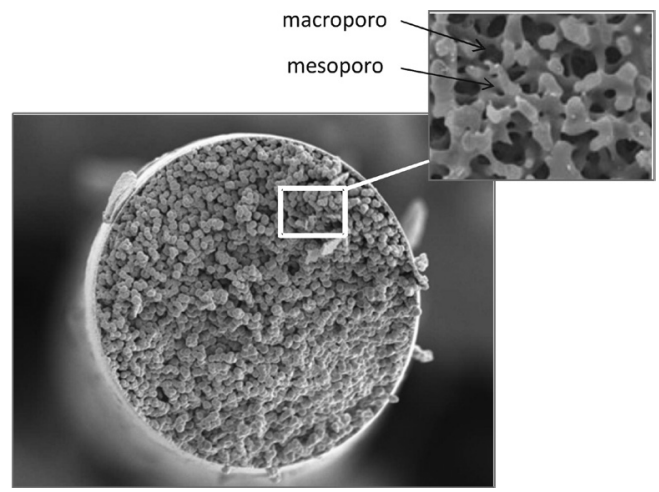

Figura 3. Corte transversal do bastão cilíndrico de sílica monolítica e sua ampliação

\section{Óxidos metálicos}

O uso de óxidos metálicos, como alumina, titânia e zircônia e, mais recentemente, os óxidos de cério e tório, como suportes cromatográficos deve-se a duas características principais, a estabilidade química e a excelente estabilidade térmica desses materiais. ${ }^{9,10,13,47}$ Além disso, esses óxidos metálicos se comportam como trocadores iônicos anfóteros, catiônicos ou aniônicos, dependendo do $\mathrm{pH}$ da FM. Outra diferença, a qual tem um grande impacto no uso das FE baseadas em óxidos metálicos, é a existência de sítios ácidos de Lewis na superfície dos óxidos, que são responsáveis pela habilidade de troca iônica dessas FE. ${ }^{48,49}$ Devido à combinação do mecanismo de retenção em fase reversa e troca iônica, as FE baseadas em óxidos metálicos, quase sempre, apresentam retenção de modo misto e, consequentemente, seletividade variada.

A alumina foi o primeiro óxido metálico empregado como suporte cromatográfico, primeiramente em separações em FN e posterior- mente modificada por recobrimento polimérico para ser utilizada em separações em FR, impulsionada pela sua estabilidade química em uma extensa faixa de $\mathrm{pH}$ (1-12). Entretanto, devido às propriedades de retenção da alumina serem muito parecidas com as da sílica, e por apresentar desempenho cromatográfico inferior, estes materiais foram pouco explorados em aplicações em separações em fase reversa. ${ }^{48,50}$

A zircônia é o óxido metálico mais estudado e difundido por apresentar maior estabilidade química e térmica, na faixa de $\mathrm{pH}$ de 1 a 14 e em temperaturas de até $200^{\circ} \mathrm{C}$, respectivamente, e, também, alta resistência mecânica. ${ }^{13,51,52} \mathrm{~A}$ coluna zirconizada mais popular disponível comercialmente é a ZirChrom ${ }^{\circledR}$-PBD (zircônia recoberta com polibutadieno) da ZirChrom ${ }^{\circledR}{ }^{\circledR}{ }^{47,49,53}$

A titânia tende a ter propriedades e mecanismos de retenção similares à zircônia. Entretanto, existem poucas informações a respeito da titânia e das vantagens como suporte cromatográfico, e, até o momento, poucas aplicações envolvendo FE baseadas em titânia têm sido publicadas. ${ }^{48}$ A ZirChrom ${ }^{\circledR}$ comercializa uma coluna de titânia recoberta com polietileno $\left(\mathrm{TiO}_{2}-\mathrm{PE}\right)$, denominada de Sachtopore ${ }^{\circledR}$ $\mathrm{RP}$, que pode ser empregada como alternativa à ZirChrom ${ }^{\circledR}$-PBD.

Entretanto, a dificuldade de obtenção das partículas dos óxidos metálicos com as propriedades requeridas para um suporte cromatográfico, e também a dificuldade de modificação química ou a organofuncionalização da sua superfície, devido à carência de grupos livres aptos a interagiram para a formação de ligações, levou ao desenvolvimento paralelo de óxidos mistos. ${ }^{8-10}$

\section{Óxidos mistos}

Os óxidos mistos são suportes cromatográficos obtidos pela mistura de sílica e de óxido metálico, e, desta forma, combinam as propriedades da sílica, como a área superficial alta, a boa estrutura de poros e a variedade de distribuição de tamanhos, com as propriedades dos óxidos metálicos, como a estabilidade química e térmica. ${ }^{54,55}$ Como resultado obtêm-se materiais cromatográficos baseados em sílica com estabilidade química e térmica aumentada. Entretanto, o desafio continua sendo o desenvolvimento de métodos de preparo que resultem em partículas com boas propriedades cromatográficas. $\mathrm{Na}$ literatura são reportados diversos estudos nos quais foram desenvolvidas FE baseadas em óxidos mistos, que apresentam maior estabilidade química e térmica, podendo-se destacar as pesquisas realizadas no LabCrom (Laboratório de Pesquisas em Cromatografia Líquida do Instituto de Química da Unicamp), onde vêm sendo desenvolvidas FE baseadas em óxidos mistos de sílica e zircônia e de sílica e titânia recobertas por diferentes polímeros orgânicos, como o PBD, poli(metiltetradecilsiloxano) (PMTDS) e poli(metiloctilsiloxano) (PMOS) e também organofuncionalizadas com C18 e com um grupo octadecil com um grupo ureia embutido (C18 ureia). A descrição detalhada desses materiais pode ser encontrada nas revisões publicadas por Faria et al. ${ }^{5,54} \mathrm{e}$ Silva et al. ${ }^{56} \mathrm{e}$ nos trabalhos publicados por Collins et al. ${ }^{4}$ e Silva et al. ${ }^{57,58}$

\section{ESTRATÉGIAS NO PREPARO DAS FASES ESTACIONÁRIAS}

Além das alternativas descritas para o aumento da estabilidade e da seletividade das FE baseadas em novos suportes cromatográficos, novas estratégias têm sido empregadas no preparo das FE modernas, com destaque para as reações de capeamento, as fases estacionárias estericamente protegidas e as fases estacionárias bidentadas.

O capeamento consiste em uma reação de silanização com um ou mais reagentes organossilanos de tamanho reduzido, geralmente trimetilclorossilano (TMCS) e/ou hexametildissilazano (HMDS), após a qual se tem um aumento do recobrimento do suporte croma- 
tográfico e uma redução do número de silanois residuais. ${ }^{59-61}$ Esta reação é realizada em uma etapa subsequente ao processo de preparo da FE. A melhora na seletividade ocorre devido à redução da interação analito-silanol e o aumento da estabilidade da FE em pH alto (> 8) é devida ao recobrimento mais homogêneo do suporte cromatográfico. $\mathrm{O}$ processo de capeamento tem sido extensivamente empregado no preparo das FE modernas, porque age como um "complemento" para o desempenho cromatográfico dessas FE e, também, porque o emprego dessas reações independe do suporte cromatográfico e do tipo da fase ligada.

$\mathrm{O}$ artifício envolvido nas FE estericamente protegidas ${ }^{2,62,63}$ é o emprego de organossilanos que possuem grupos volumosos, como o isopropil ou o isobutil, ligados ao átomo de silício no início da cadeia de substituição. Estes grupos volumosos próximos à superfície da sílica fornecem uma maior proteção à ligação siloxano, evitando a quebra entre a fase ligada e o suporte cromatográfico, quando são empregadas FM com pH menores que 2. As FE estericamente protegidas disponíveis comercialmente são produzidas pela Agilent Technologies, denominadas de Zorbax StableBond ${ }^{\circledR}{ }^{64}$

As FE bidentadas ${ }^{2,62,65}$ são preparadas a partir de silanos bidentados formados por dois átomos de silício interligados entre si por um grupo etil ou propil. Estas FE possuem estabilidade química para serem empregadas com FM com $\mathrm{pH}$ acima de 8, uma vez que o acesso aos grupos silanois é reduzido. Estas FE também são comercializadas pela Agilent Technologies, com o nome de Zorbax Extend-C18 ${ }^{\circledR}{ }^{66}$

\section{AVANÇOS NA SELETIVIDADE DAS FASES ESTACIONÁRIAS MODERNAS}

A seletividade é o requisito de maior relevância no processo cromatográfico. ${ }^{67}$ Mais especificamente, nas separações por CLAE, a seletividade é influenciada por quatro variáveis: a fase estacionária; a composição da fase móvel; as condições físicas (temperatura e pressão) e, a natureza dos compostos a serem analisados.

No caso da FE, que é a variável proeminente, a seletividade é influenciada por uma série de fatores, destacando-se: as características da fase ligada, a presença de grupos silanois residuais e a realização do capeamento. A forma, o tamanho e a distribuição das partículas do suporte cromatográfico, as dimensões da coluna e o seu processo de enchimento também exercem influência na seletividade. ${ }^{68}$

Conforme mencionado, a seletividade da FE é dependente de um conjunto de fatores, entretanto, o principal motivador no desenvolvimento de FE com diferentes seletividades está relacionado com a dificuldade encontrada nas separações de compostos polares, que engloba a maioria dos compostos básicos, por CLAE-FR empregando FE puramente alifáticas. ${ }^{69-71}$ Esta dificuldade é decorrente de dois fatores principais: estes compostos são retidos insuficientemente na FE (que possui características hidrofóbicas); estes compostos interagem fortemente com os grupos silanois residuais da FE (que possuem características ácidas) resultando em picos cromatográficos com cauda acentuada, levando, inclusive, a retenções irreversíveis na fase estacionária. A retenção dos compostos polares pode ser aumentada com o uso de FM com altas quantidades de água, porém, o uso de FM com porcentagens de água acima de $95 \%$ leva à falência da coluna cromatográfica, além de ser incompatível com a detecção por EM. A principal estratégia para diminuir as interações entre os compostos básicos e os grupos silanois residuais é o uso de tampões inorgânicos em condições alcalinas ou ácidas. No entanto, conforme discutido anteriormente, a estabilidade das FE baseadas em sílica é limitada a uma faixa estreita de $\mathrm{pH}$ (2 a 8) e, além disso, o uso de tampões inorgânicos implica numa série de cuidados tanto com o sistema quanto com as colunas cromatográficas, uma vez que a precipitação desses sais, que ocorre quando o tampão não é eliminado do sistema cromatográfico antes do seu desligamento, diminui significativamente o tempo de vida de ambos. O uso de sais inorgânicos é incompatível também com os detectores por EM.

Em vista disso, são buscadas alternativas a estas limitações, com o propósito de desenvolver FE que possuam as características necessárias para que as separações de compostos de diferentes naturezas sejam possíveis. Dentre estas, podem-se destacar as FE com grupo polar embutido, fenil, fluoradas, de modo misto e de interação hidrofílica.

\section{Fases estacionárias com grupo polar embutido}

As FE com grupo polar embutido (GPE) possuem um grupo polar inserido na cadeia alquila, geralmente após o terceiro grupo metileno ligado ao átomo de silício do organossilano imobilizado. Na Figura 4A está exemplificada a estrutura de uma FE com GPE. Comumente, os grupos polares empregados nestas FE são capazes de estabelecer ligação de hidrogênio, como os grupos carbamato, amida, amina, ureia e éter, deixando estas FE com um caráter mais "básico". 2,62,72,73

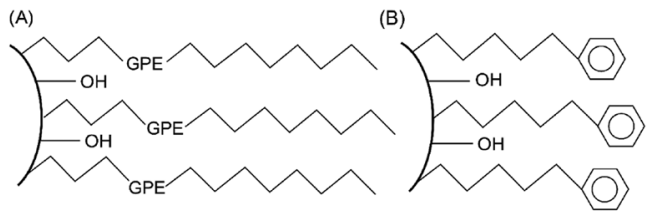

(C)

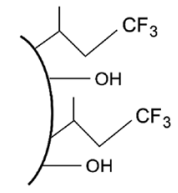

(D)

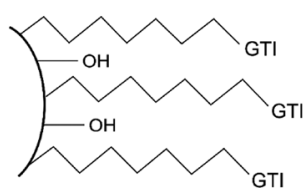

(E)

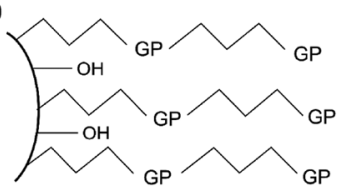

Figura 4. Exemplos de estruturas de algumas FE (A) com grupo polar embutido (GPE), (B) fenil, (C) fluorada, (D) de modo misto e com grupo trocador iônico (GTI) e (E) HILIC com grupo polar (GP)

O primeiro trabalho que reporta o preparo de uma FE com um grupo amida embutido foi publicado por Nomura et al. ${ }^{74} \mathrm{em} 1987$. Logo depois, Ascah e Feibush ${ }^{75}$ também desenvolveram uma FE com um grupo amida embutido, que foi a primeira FE com GPE comercializada, com o nome de Supelcosil ABZ (Supelco). Hoje estes tipos de FE são comercializados por praticamente todos os fabricantes de colunas e, devido às diferenças na seletividade resultante da presença dos grupos polares, têm sido consideradas complementares às FE clássicas (C8 e C18), que são as FE mais difundidas e empregadas nas separações rotineiras por CLAE-FR.

As principais características apresentadas pelas FE com GPE são: (i) mantêm o caráter de FR; ${ }^{76,77}$ (ii) fornecem uma seletividade diferenciada quando comparada com a FE alquila, ${ }^{73,76-78}$ pois os analitos polares e básicos ficam menos retidos nas FE com GPE, uma vez que ocorre uma blindagem dos grupos silanois residuais, pelo grupo polar, enquanto que os analitos passíveis de estabelecer ligação de hidrogênio, como os fenóis, as sulfonamidas, os ácidos carboxílicos não ionizados entre outros, ficam mais retidos, devido às interações por ligações de hidrogênio entre estes compostos e o grupo polar presente na FE; (iii) são compatíveis com o uso de FM com altas porcentagens do solvente aquoso ${ }^{2,73,76,77,79-81}$ podendo serem usadas até mesmo com $100 \%$ de água sem ocorrer o colapso da FE, ou 
seja, a perda da sustentação das cadeias da fase ligada. O fenômeno do colapso da FE é muito comum nas FE clássicas se não for usado pelo menos de 5 a $10 \%$ de solvente orgânico na composição da FM, porque pode ocorrer a expulsão da FM dos poros, resultando em perda de retenção. Entretanto, nas FE com GPE isso não ocorre devido à maior solvatação da superfície da FE proveniente das interações, por ligações de hidrogênio, entre os grupos polares e as moléculas de água. Esta característica é especialmente útil para a retenção de compostos polares e promove uma melhora no desempenho cromatográfico (retenção reprodutível e estável) e um rápido re-equilíbrio da FE após a eluição por gradiente; (iv) a atividade silanofílica é suprimida ${ }^{73,76,77,79-81}$ e, dessa forma, os compostos básicos são eluídos em picos simétricos, particularmente em valores intermediários de $\mathrm{pH}$. Têm sido propostos quatro mecanismos diferentes ${ }^{2,77,80}$ para explicar esta menor interação entre os compostos básicos e os grupos silanois residuais: interação, por ligações de hidrogênio, entre os grupos polares embutidos e os grupos silanois, bloqueando o acesso dos analitos de interesse aos grupos silanois residuais; interação, por ligações de hidrogênio, entre o grupo polar embutido e as moléculas de água, criando uma camada de água firmemente ligada ao redor do grupo polar embutido, enfraquecendo as interações entre o analito e os grupos silanois residuais; interação preferencial do analito com os grupos polares embutidos ao invés da interação com os silanois residuais e, interação, por ligações de hidrogênio, entre os grupos polares de cadeias adjacentes, blindando o acesso aos grupos silanois.

Em vista destas características, as FE com GPE podem ser consideradas uma alternativa às FE clássicas, especialmente para a separação de compostos polares e básicos. Um exemplo do potencial apresentado pelas FE com GPE na separação de compostos básicos está ilustrado na Figura 5, na qual estão apresentados os cromatogramas da separação de três benzodiazepínicos em uma coluna recheada com FE C18 com um grupo tiocarbamato embutido e em uma coluna recheada com FE C18 tradicional empregando as mesmas condições cromatográficas. ${ }^{82}$ Comparando-se a separação dos compostos nas duas colunas pode-se verificar que na coluna recheada com FE C18 com GPE todos os compostos foram separados com picos simétricos e com boa resolução usando uma FM sem ajuste de $\mathrm{pH}$, enquanto que na coluna recheada com FE C18 os compostos eluíram em picos assimétricos e com pouca resolução.

\section{Fases estacionárias fenil}

Estas FE contêm grupos fenil inseridos na sua estrutura. As FE fenil diferenciam-se entre si pelos níveis de aromaticidade e de hidrofobicidade decorrentes de modificações na sua estrutura. ${ }^{83,84}$ Estas modificações incluem: a cadeia entre o átomo de silício e o anel aromático pode variar de 0 a 6 grupos metilênicos; a FE pode ter um ou dois anéis aromáticos ligados à cadeia ou entre si e, a FE pode conter um heteroátomo na cadeia entre o suporte cromatográfico e o anel aromático. Na Figura 4B está exemplificada a estrutura de uma FE fenil.

Neimark e Chertov ${ }^{85}$ foram os primeiros a tentar ligar grupos fenil na superfície da sílica usando feniltriclorossilano e difenildiclorossilano e hoje, encontra-se disponível uma série de FE fenil com características diferenciadas, como etil, propil ou hexil-fenil, flúor-fenil e bifenil, dentre outras. ${ }^{86,87}$

O aumento da popularidade das FE fenil reside em seu potencial de seletividade cromatográfica diferenciada, quando comparadas com as FE alquila tradicionais, atribuído a sua capacidade de formar ligações $\pi$ - $\pi$ com os compostos aromáticos. ${ }^{86,87}$

A interação $\pi$ - $\pi$ é um tipo de interação de elétron doador-aceptor, proveniente de sistemas com elétrons $\pi$, quer através de interações inter ou intramoleculares. ${ }^{83,88}$ No caso das separações cromatográficas,
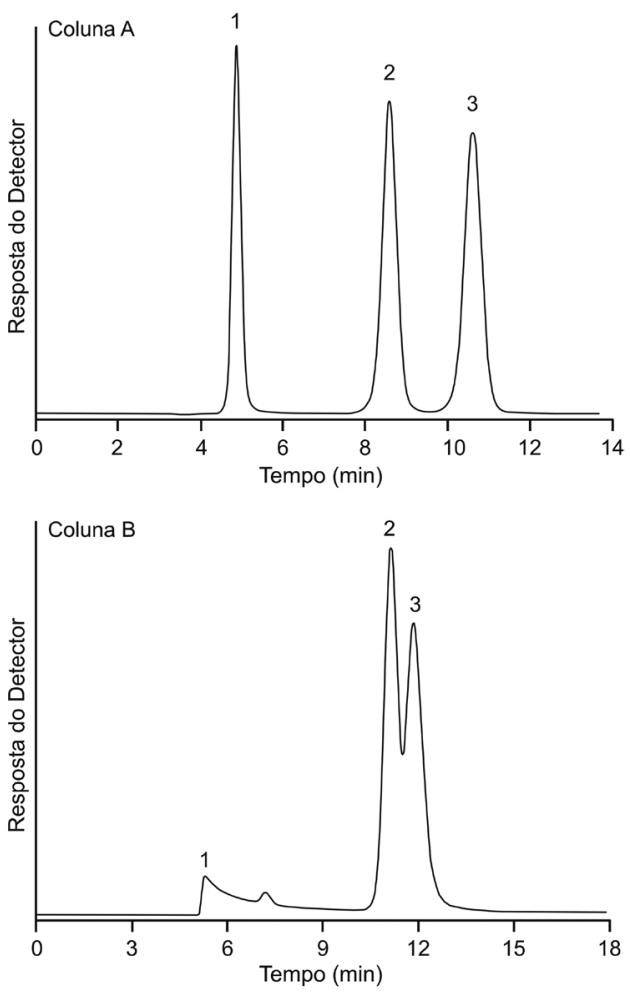

Figura 5. Cromatogramas da separação de uma mistura de benzodiazepínicos nas seguintes colunas: Coluna A: C18 com GPE, 5 um (60 mm x 4,2 mm

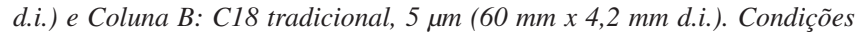
cromatográficas para ambas as colunas: volume de injeção: $5 \mu \mathrm{L}$, fase móvel: metanol:água $(50: 50 \mathrm{v} / \mathrm{v})$, vazão: $0,8 \mathrm{~mL} \mathrm{~min} \mathrm{~m}^{-1}$, detecção UV: $220 \mathrm{~nm}$, temperatura: $25^{\circ}$ C. Identificação dos picos: 1 - bromazepam, 2 -alprazolam e 3 - lorazepam. Adaptada da ref. 82

estas interações podem acontecer entre os elétrons $\pi$ da FE, que é a fonte doadora de elétrons, e os elétrons $\pi$ dos compostos em análise, que são os receptores dos elétrons. Isto torna essas FE muito seletivas para a separação de compostos aromáticos, com destaque para os polinucleares e nitroaromáticos..$^{87,89}$

Uma observação interessante a respeito dessas FE refere-se à influência exercida pelo modificador orgânico da FM na seletividade de separação. ${ }^{72,84,88}$ A seletividade dos compostos aromáticos varia conforme o solvente orgânico empregado na FM. Considerando-se os dois solventes mais comumente usados nas separações em FR, acetonitrila e metanol, a acetonitrila apresenta menor seletividade. Esta menor seletividade apresentada pela acetonitrila, quando comparada com o metanol, é devida à presença do grupo nitrila e, desta maneira, pode formar complexos elétron doador - aceptor com a FE ou com os compostos em análise, dependendo de qual é a contraparte mais deficiente em elétrons, suprimindo as interações entre os compostos em análise e a FE.

\section{Fases estacionárias fluoradas}

As FE fluoradas, assim denominadas por possuírem átomos de flúor ligados à cadeia alquila ou a grupos fenil, são mais uma alternativa às FE tradicionais $\mathrm{C} 8$ e C18, por apresentarem uma seletividade única proveniente das propriedades específicas das ligações $\mathrm{C}-\mathrm{F}$ que promovem um aumento no caráter dipolar da $\mathrm{FE}$, o que intensifica a interação com compostos polares, e, dessa forma, as separações não ocorrem por um mecanismo de interação simples de FR..$^{90-93}$ Na Figura 4C está exemplificada a estrutura de uma FE fluorada.

$\mathrm{O}$ primeiro trabalho sobre FE fluoradas à base de sílica para 
CLAE-FR foi publicado no início dos anos 80 por Berendsen et al.,${ }^{94}$ no qual foi preparada uma FE ((heptadecafluordecil)dimetilsilil) (HFD) que foi comparada com as FE $n$-propil e $n$-decil, na separação de compostos fluorados e não fluorados. O resultado deste estudo mostrou que a FE fluorada apresentou maior interação com os compostos fluorados que as FE não fluoradas. Estes resultados despertaram o interesse em investigar estas FE e uma série de estudos ${ }^{95-101}$ estão sendo realizados em vista da especificidade destas FE, principalmente comparando-as com as FE não fluoradas.

As principais características apresentadas pelas FE fluoradas ${ }^{93,95}$ quando comparadas com as FE C8 e C18 são: a maioria dos hidrocarbonetos apresentam menor retenção; muitos compostos fluorados apresentam igual ou maior retenção; ésteres e cetonas são mais retidos; misturas contendo compostos fluorados e não fluorados são melhores separadas; altas quantidades de solvente orgânico podem aumentar a retenção de muitos compostos, incluindo as bases orgânicas, sendo esta composição de FM muito útil para análises por CL-EM, na qual o aumento da quantidade de solvente orgânico aumenta a detectabilidade.

Os mecanismos que regem as separações nas FE fluoradas ainda não foram claramente definidos, entretanto, muitos mecanismos têm sido propostos como também outras características têm sido atribuídas às FE fluoradas. Yamamoto e Rokushika ${ }^{96}$ avaliaram o comportamento de retenção de compostos aromáticos em FE fluoradas e verificaram que: em altas concentrações de metanol na composição da FM ocorre a inversão da ordem de eluição do antraceno e do benzeno; existem interações moleculares exclusivas entre as moléculas aromáticas e a FE fluorada, que são mais fortes para a retenção de compostos planares e rígidos que para compostos não planares e aumentam conforme aumenta o número de anéis aromáticos e, a menor retenção dos compostos aromáticos nas FE fluoradas, quando comparadas com as FE alquila, é devida à menor energia necessária para a formação da ligação entre o composto aromático e a FE fluorada. É sugerido nesse estudo que a ligação entre os compostos aromáticos e a FE fluorada se dá por interações eletrostáticas entre os elétrons $\pi$ dos anéis aromáticos e um dos pares de elétrons disponíveis no átomo de flúor, que aumentam conforme aumenta o número de elétrons $\pi$ nos anéis aromáticos.

Marchand et al. ${ }^{91}$ sugerem que a seletividade das FE fluoradas comparadas com as FE alquila pode ser explicada, pelo menos em parte, como consequência da baixa polarizabilidade dos ligantes fluorados, como mensurado pelos seus baixos valores de índices de refração (IR) comparados com os ligantes alquila. Menor polarizabilidade significa interações via forças dispersivas reduzidas, com consequências para a retenção que pode ser interpretada qualitativamente em termos dos parâmetros do modelo de solubilidade, ou seja, compostos e FE com IR similares exibem interação e retenção preferencial. Os IR aumentam nesta ordem: compostos fluorados < compostos alifáticos < compostos aromáticos < compostos poliaromáticos, sugerindo que a retenção relativa destes compostos nas FE alquila (mais altos IR) versus as FE fluoradas (mais baixos IR) tende a aumentar na mesma ordem.

Bell e Daniel Jones ${ }^{97}$ sugerem que as FE fluoradas apresentam o mecanismo de retenção $U$-Shape, ou seja, apresentam mecanismo de retenção de fase reversa e de fase normal para compostos polares, dependendo da quantidade de modificador orgânico na composição da FM. À medida que se aumenta a quantidade de solvente orgânico na composição da FM, ocorre uma diminuição da retenção dos compostos básicos (FR) e, após certo ponto, ocorre o aumento da retenção dos compostos básicos (FN). Uma possível explicação para o mecanismo de $U$-Shape nas FE fluoradas é que em altas quantidades de solvente orgânico, a FE está solvatada e um número maior de silanois residuais está acessível para interagir por mecanismos de troca iônica com os compostos polares. Estes autores ${ }^{97}$ verificaram também que compostos básicos ficam mais retidos nas FE fluoradas quando comparadas com as FE alquila e de sílica. Eles sugerem que ocorrem simultaneamente interações eletrostáticas entre os compostos e os grupos silanois ionizados e interações hidrofóbicas com as cadeias alquila da FE ou polares com os átomos de flúor, que resultam nessa maior retenção.

Cabe ressaltar, ainda, que alguns estudos apontaram as FE fluoradas como sendo muito úteis para a separação de compostos isoméricos. ${ }^{98-101} \mathrm{Um}$ exemplo deste tipo está ilustrado na Figura 6, na qual estão apresentados os cromatogramas da separação de uma mistura de difluorfenóis, que são isômeros de posição, em uma coluna recheada com uma FE fluorada e em uma coluna recheada com uma FE C8 empregando as mesmas condições cromatográficas. Os cromatogramas resultantes mostram que apenas a FE fluorada foi seletiva para a separação de todos os compostos, e, além disso, em um menor tempo de análise.

Em vista de todos estes estudos pode-se verificar que as FE fluoradas apresentam interações diferenciadas com diversos tipos de compostos e, hoje, estas FE estão em ascensão e em 2008 já eram comercializadas, por pelo menos seis fabricantes, colunas recheadas com diferentes tipos de FE fluoradas. ${ }^{95}$
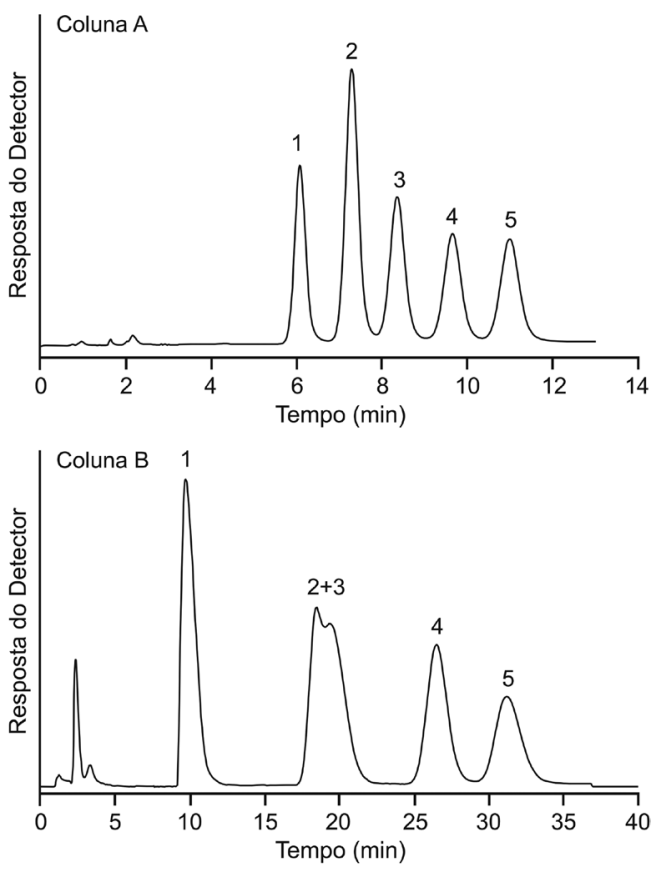

Figura 6. Cromatogramas da separação da mistura de difluorfenóis nas seguintes colunas: Coluna A: fluorada, 5 m (60 mm x 3,1 mm d.i.) e Coluna B: C8 tradicional, $5 \mu \mathrm{m}$ (60 mm x 3,1 mm d.i.). Condições cromatográficas para ambas as colunas: volume de injeção: $5 \mu \mathrm{L}$, fase móvel: acetonitrila:água (20:80 v/v), vazão: 0,3 mL min ${ }^{-1}$, detecção UV: $254 \mathrm{~nm}$, temperatura ambiente. Identificação dos picos: 1 - 2,6 - difluorfenol, 2 - 2,4 - difluorfenol, 3-2,3 difluorfenol, 4-3,4 - difluorfenol e 5-3,5 - difluorfenol. Adaptada da ref. 101

\section{Fases estacionárias de modo misto}

As FE denominadas de modo misto possuem grupos trocadores iônicos inseridos nas cadeias alquila e, desta forma, combinam os princípios de separação ortogonal de fase reversa e de troca iônica, oferecendo um potencial de otimização de separação de misturas complexas (por exemplo, formadas por compostos orgânicos altamente polares, ionizáveis ou iônicos e outros compostos hidrofóbicos) muito maior que as FE reversas clássicas. ${ }^{86,102-105}$ Os grupos trocadores 
iônicos podem ser grupos catiônicos ou aniônicos. De forma geral, os compostos neutros interagem com a FE de modo misto por mecanismo de FR, enquanto que os compostos básicos interagem por mecanismo de troca iônica, de exclusão iônica ou de interação hidrofílica nas FE com grupos trocadores catiônicos, aniônicos e hidrofílicos, respectivamente. Similarmente, os compostos ácidos podem interagir por interações de troca iônica e exclusão iônica nas FE com grupos trocadores aniônicos ou catiônicos, respectivamente. ${ }^{106-108} \mathrm{Na}$ Figura 4D está exemplificada a estrutura de uma FE de modo misto.

$\mathrm{O}$ grande diferencial dessas FE de modo misto é que a seletividade ou a força das interações entre os compostos e os sítios trocadores iônicos pode ser ajustada pela ativação ou desativação destes grupos, através da variação de alguns parâmetros como a natureza e a quantidade do modificador orgânico na FM, o tipo e a concentração do tampão, adição de aditivos na FM e variações no pH e na temperatura. ${ }^{102,105,106,108}$

Apesar dos sorventes de extração em fase sólida (EFS) de modo misto serem bastante conhecidos ${ }^{103} \mathrm{e}$ o primeiro trabalho reportando o preparo de uma coluna cromatográfica de modo misto baseada em sílica ter sido publicado no início dos anos $60,{ }^{109}$ somente recentemente as FE de modo misto começaram a ganhar destaque em CLAE, ao serem introduzidas comercialmente pela SIELC Technologies, com o nome de Primesep. ${ }^{110}$ Em seguida, a Dionex também desenvolveu fases estacionárias de modo misto, denominadas de Acclaim ${ }^{\circledR},{ }^{111} \mathrm{e}$ hoje, estes dois fabricantes dominam o mercado deste tipo de FE.

As principais vantagens apontadas para as FE de modo misto são: capacidade superior para separar compostos iônicos; controle total da seletividade; múltiplos modos de separação, incluindo fase reversa, fase normal e troca iônica e, uma extensa gama de aplicações que inclui a separação de aminoácidos, ácidos nucleicos, peptídeos e proteínas, e também a separação de compostos farmacêuticos. Estas FE vêm sendo também usadas com sucesso como a segunda coluna em cromatografia líquida bidimensional. ${ }^{104,106,107,112}$

Cabe ressaltar que existe uma controvérsia entre os fabricantes referente à denominação das FE de modo misto e das de interação hidrofílica, que serão apresentadas a seguir, uma vez que ambas podem ser empregadas no modo de separação de interação hidrofílica. Entretanto, a diferença básica entre elas reside no fato que as FE de modo misto são empregadas principalmente para a separação de compostos ionizáveis, enquanto que as FE de interação hidrofílica são aplicadas na análise de compostos moleculares.

\section{Fases estacionárias HILIC}

As FE denominadas de HILIC são empregadas em cromatografia de interação hidrofílica (HILIC - hydrophilic interaction chromatography). A cromatografia por interação hidrofílica é uma modalidade de separação na qual é empregada uma FE polar e uma FM menos polar. ${ }^{113-116}$ Entretanto, ao contrário da cromatografia líquida em fase normal, a FM em HILIC é composta por uma mistura contendo uma porcentagem alta de solvente orgânico (geralmente acetonitrila, podendo também ser usado metanol ou acetona) e uma porcentagem relativamente pequena de água, uma vez que, neste caso, a água é o solvente mais forte. O fato da HILIC ser uma variação da cromatografia líquida em fase normal, na qual também se empregam FE polares, porém com FM constituídas apenas por solventes orgânicos de baixa polaridade (geralmente hexano, com pequenas quantidades de solventes menos apolares), ela também tem sido definida como cromatografia líquida de "fase reversa reversa" ou de "fase normal aquosa". ${ }^{113,116}$

O principal mecanismo de interação que rege as separações em HILIC é o de partição. ${ }^{113-116}$ A alta polaridade da FE associada ao uso de uma FM contendo água leva à formação de uma camada de água que fica imobilizada na superfície da FE, e, por causa disso, o composto em análise estabelece um equilíbrio com esta camada de água e a FM que possui caráter mais hidrofóbico.

Desta forma, as FE HILIC possuem necessariamente características polares, podendo ser constituídas de sílica ou outros suportes cromatográficos modificados ou não. ${ }^{113-115}$ No caso dos suportes modificados, os principais grupos que são ligados às cadeias alquila são: amino, amida, diol, ciano, sulfobetaína e ciclodextrina. Na Figura 4E está exemplificada a estrutura de uma FE HILIC.

Embora esta modalidade de separação tenha sido usada pela primeira vez em 1975, por Linden e Lawhead ${ }^{117}$ na separação de carboidratos, empregando uma FE baseada em sílica com grupos amino e uma FM composta de uma mistura de acetonitrila e água, foi somente em 1990 que esta modalidade de separação recebeu a denominação de HILIC, proposta por Alpert. ${ }^{118}$ Segundo Alpert, o termo HILIC deve ser empregado se o solvente de eluição forte for a água e o mecanismo de retenção for a partição. Só recentemente a HILIC vem ganhando aceitação e sendo empregada para a separação de compostos polares em diferentes áreas de aplicação, como a química farmacêutica, agrícola, alimentícia, medicinal, proteômica e metabolômica. ${ }^{13-115,119}$

Essa grande ascensão da HILIC nos últimos anos para análise de compostos polares se deve às vantagens que esta modalidade de separação apresenta em relação à cromatografia líquida em FN e FR e, também, ao desenvolvimento de um grande número de FE HILIC, que vêm sendo comercializadas por praticamente todos os fabricantes de colunas cromatográficas. ${ }^{13,114,120,121}$ Em relação às separações em FN, as principais vantagens apresentadas são: melhor solubilidade dos compostos polares, que usualmente possuem baixa solubilidade nos solventes apolares empregados em FN e, possibilidade de ser empregada em análises com detecção por EM, uma vez que a ionização usando uma FM orgânica apolar não é facilmente alcançada. Em relação às separações em FR, pode-se citar: a ordem de eluição dos compostos em HILIC é mais ou menos oposta à ordem de eluição em FR, o que indica que a HILIC retém melhor os compostos que são problemáticos de se analisar em FR; alta detectabilidade nas análises com detecção por EM devido à alta porcentagem de solvente orgânico polar empregada nas FM para HILIC e, separações mais rápidas devido a menor viscosidade da FM. Como forma de exemplificar a alta detectabilidade da HILIC nas análises com detecção por EM, na Figura 7 estão apresentados os cromatogramas de massas da separação de dois compostos polares, acetilcolina e colina, analisados em condições de fase reversa (FM com alta porcentagem de água) e de HILIC (FM com alta porcentagem de solvente orgânico), no modo de ionização por eletronebulização (ESI - eletrospray ionization). ${ }^{121}$ Comparando-se a intensidade dos picos dos compostos nos dois modos de separação, pode-se verificar um aumento significativo na detectabilidade dos dois compostos quando analisados em condições de HILIC. Isto se justifica pela composição da FM, que possui uma alta porcentagem de solvente orgânico e, dessa forma, é dessolvatada mais facilmente que uma FM com alta porcentagem de água, resultando em um aumento da resposta no EM. Além disso, a ordem de eluição dos compostos foi inversa e a retenção foi maior, sendo estas características vantajosas para a realização de separações que não foram bem sucedidas em condições de FR.

\section{CONCLUSÕES E TENDÊNCIAS FUTURAS}

As FE modernas são o resultado de anos de pesquisa em busca de FE que permitam a separação de misturas complexas com seletividade, eficiência, resolução e rapidez. Para isso, foi necessário o desenvolvimento de novos suportes cromatográficos e/ou o melhoramento dos já existentes, o desenvolvimento de novas estratégias no preparo de FE e, também, a criação de FE com diferentes funcionalidades. 

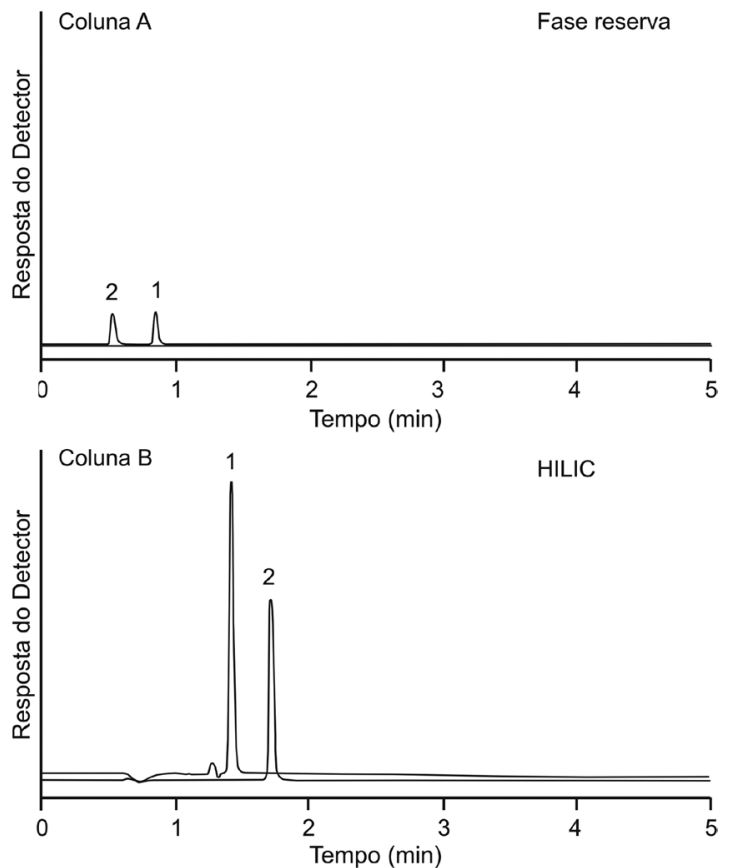

Figura 7. Cromatogramas de massas do íon selecionado da acetilcolina $(\mathrm{m} / \mathrm{z}$ 146,2) e da colina (m/z 103,9). Coluna A: Acquity UPLC BEH C18, 1,7 $\mu \mathrm{m}$

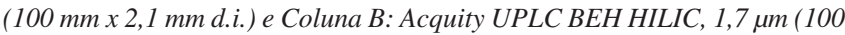
$m m \times 2,1 \mathrm{~mm}$ d.i.). Condições cromatográficas: volume de injeção: $10 \mu \mathrm{L}$; fase móvel: Coluna A: $100 \%$ de A (água com $10 \mathrm{mmol} \mathrm{L}^{-1}$ de formiato de amônio e 0,125\% de ácido fórmico) e Coluna B: A:B $(10: 90 \mathrm{v} / \mathrm{v})$, onde B corresponde à acetonitrila:metanol:água $(90: 5: 5 \mathrm{v} / \mathrm{v} / \mathrm{v}) \mathrm{com} 10 \mathrm{mmol} \mathrm{L}^{-1}$ de formiato de amônio e 0,125\% de ácido fórmico; vazão 0,5 $\mathrm{mL} \mathrm{min}^{-1}$ e detecção por $\mathrm{EM}$ no modo de ionização por eletronebulização positivo (ESI+). Identificação dos picos: 1 - acetilcolina e 2 - colina. Adaptada da ref. 121

Conforme a revisão apresentada, que traz os desenvolvimentos mais recentes a respeito de FE para CLAE-FR, pode-se concluir que muitos avanços já foram alcançados e que a disponibilidade dessas novas FE, que possuem características de seletividade e estabilidade superiores às FE existentes até então, vem permitindo a expansão do uso da CLAE-FR, bem como facilitando a separação de compostos difíceis de serem analisados, como os compostos básicos. A tendência é que esta expansão aumente conforme o emprego dessas FE se torne usual.

\section{AGRADECIMENTOS}

À FAPESP e ao CNPq pelo apoio financeiro.

\section{REFERÊNCIAS}

1. Tonhi, E.; Collins, K. E.; Jardim, I. C. S. F.; Collins, C. H.; Quim. Nova 2002, 25, 616

2. Silva, C. R.; Jardim, I. C. S. F.; Collins, C. H.; Airoldi, C.; Quim. Nova 2004, 27, 270

3. Silva, C. R.; Collins, C. H.; LCGC North Am. LC Column Technology Supplement 2008, 26, 47.

4. Collins, C. H.; Silva, C. R.; Faria, A. M.; Collins, K. E.; Jardim, I. C. S. F.; J. Braz. Chem. Soc. 2009, 20, 604.

5. Faria, A. M.; Collins, C. H.; Jardim, I. C. S. F.; J. Braz. Chem. Soc. 2009, 20, 1385.

6. Borges, E. M.; Bottoli, C. B. G; Collins, C. H.; Quim. Nova, 2010, 33, 945.

7. Unger, K. K.; Trudinger, U. Em High Performance Liquid Chromatography; Brown, P.R.; Hartwick, R. A., eds.; Wiley: New York, 1989, cap. 3 .
8. Dun, H.; Zhang, W.; Wey, Y.; Xiuqing, S.; Li, Y.; Chen, L.; Anal. Chem. 2004, 76, 5016.

9. Nawrocki, J.; Dunlap, C.; McCormick, A.; Carr, P. W.; J. Chromatogr., A 2004, 1028, 1.

10. Nawrocki, J.; Dunlap, C.; Li, J.; Zhao, J.; McNeff, C. V.; McCormick, A.; Carr, P. W.; J. Chromatogr., A 2004, 1028, 31.

11. Luo, H.; Carr, P. W.; Anal. Bioanal. Chem. 2008, 391, 919.

12. Zizkovsky, V.; Kucera, R.; Klimes, J.; Dohnal, J.; J. Chromatogr., A 2008, 1189, 83.

13. Wenclawiak, B. W.; Giegold, S.; Teutenberg, T.; Anal. Lett. 2008, 41, 1097.

14. Meyer, V. R.: Practical High-Performance Liquid Chromatography, $4^{\text {th }}$ ed., Wiley: New York, 2004.

15. Unger, K. K.; Skudas, R.; Schulte, M. M.; J. Chromatogr., A 2008, 1184, 393.

16. Guiochon, G.; J. Chromatogr., A 2006, 1126, 6.

17. Kirkland, J. J.; Truszkowski, F. A.; Ricker, R. D.; J. Chromatogr., A 2002, 965,25

18. Stella, C.; Rudaz, S.; Veuthey, J. L.; Tchapla, A.; Chromatographia Suppl. 2001, 53, S113.

19. Nawrocki, J.; J. Chromatogr., A 1997, 779, 29.

20. Nawrocki, J.; Moir, D. L.; Szczepaniak, W.; Chromatographia 1989, 28 , 143.

21. Lesellier, E.; West, C.; J. Chromatogr., A 2007, 1158, 329.

22. Pesek, J. J.; Matyska, M. T.; J. Sep. Sci. 2005, 28, 1845.

23. Gritti, F.; Perdu, C.; Guiochon, G.; J. Chromatogr., A 2008, 1180, 73.

24. http://www.microsolvtech.com/hplc/typec_about3.asp, acessada em Agosto 2009 e Junho 2010.

25. Cheng, Y. F.; Walter, T .H.; Lu, Z.; Iraneta, P.; Alden, B. A.; Gandreau, C.; Grassi, J. M.; Carmody, J. L.; O'Gara, J. E.; Fisk, R. P.; LC-GC North Am. 2000, 18, 1162.

26. Wyndham, K. D.; O'Gara, J. E.; Walter, T. H.; Glose, K. H.; Lawrence, N. L.; Alden, B. A.; Izzo, G. S.; Hudalla, C. J.; Iraneta. P. C.; Anal. Chem. 2003, 75, 6781.

27. Liu, Y.; Grinberg, N.; Thompson, K. C.; Wenslow, R. M.; Neue, U. D.; Morrison, D.; Walter, T. H.; O'Gara, J. E.; Wyndham K. D.; Anal. Chim. Acta 2005, 554, 144.

28. Maldaner, L.; Jardim, I. C. S. F.; Quim. Nova 2009, 32, 214.

29. Vanhoenacker, G.; Sandra, P.; Anal. Bioanal. Chem. 2008, 390, 245.

30. Teutenberg, T.; Hollebekkers, K.; Wiese, S.; Boergers, A.; J. Sep. Sci. 2009, 32, 1262.

31. http://www.instrument.com.cn/Quotation/Manual/103842.pdf, acessada Junho 2010.

32. http://www.kromasil.com/kromasil/opencms/eternity/about.html, acessada em Agosto 2009 e Junho 2010.

33. http://www.selerity.com/main/main_products_hplc_acc.html, acessada em Outubro 2009 e Junho 2010.

34. http://www.selerity.com/main/Documents/TechNote811.pdf, acessada em Outubro 2009 e Junho 2010.

35. Fekete, S.; Fekete, J.; Ganzler, K.; J. Pharm. Biomed. Anal. 2009, 50, 703.

36. Cunliffe, J. M.; Maloney, T. D.; J. Sep. Sci. 2007, 30, 3104.

37. Kirkland, J. J.; Truszkowski, F. A.; Dilks Jr., C. H.; Engel, G. S.; J. Chromatogr., A 2000, 890, 3.

38. http://www.chem.agilent.com/en-us/products/consumables/columns/ lcandlc-ms/pages/default.aspx, acessada em Agosto 2009 e Junho 2010.

39. http://www.advanced-materials-tech.com/halo.html, acessada em Agosto 2009 e Junho 2010.

40. http://www.sigmaaldrich.com/express, acessada em Agosto 2009 e Junho 2010.

41. http://www.phenomenex.com/Phen/EM/ws63990808/technology.html, acessada em Outubro 2009 e Junho 2010.

42. Faria, A. M.; Bottoli, C. B. G.; Jardim, I. C. S. F.; Collins, C. H.; Quim. Nova 2006, 29, 300. 
43. Miller, S.; Anal. Chem. 2004, 76, 99A.

44. Ikegami, T.; Tanaka, N.; Curr. Opin. Chem. Biol. 2004, 8, 527.

45. http://www.merck-chemicals.com.br/colunas-de-hplc-chromolith-/c_oUeb. s1LrkgAAAEWq.AfVhTl, acessada em Outubro 2009 e Junho 2010.

46. http://www.phenomenex.com/cms400min/oxymonolithic.aspx, acessada em Outubro 2009 e Junho 2010.

47. Zizkovsky, V. Kucera, R.; Klimes, J.; J. Pharm. Biomed. Anal. 2007, 44, 1048 .

48. Zizkovsky, V.; Kucera, R.; Klimes, J.; Dohnal, J.; J. Chromatogr., A 2008, 1189, 83.

49. Dunlap, C. J.; McNeff, C. V.; Stoll, D.; Carr, P. W.; Anal. Chem. 2001, $1,599$.

50. Pesek, J. J.; Matyska, M. T.; J. Chromatogr., A 2002, 952, 1.

51. Baldean-Galea, M. S.; Jandera, P.; Hodisan, S.; J. Liq. Chromatogr. Relat. Technol. 2008, 31, 807.

52. Ovens, C.; Sievwright, D.; Silcock, A. J.; J. Chromatogr, A 2006, 1137, 56.

53. Yang, Y.; LCGC North Am. LC Column Technology Supplement 2006, $24,53$.

54. Faria, A. M.; Jardim, I. C. S. F.; Collins, K. E.; Collins, C. H.; J. Sep. Sci. 2006, 29, 782.

55. Ge, J.; Zhao, L.; Shi, Y.; J. Liq. Chromatogr. Relat. Technol. 2008, 31, 151.

56. Silva, C. R.; Collins, C. H.; Collins, K. E.; Airoldi, C.; J. Sep. Sci. 2006, 29,790 .

57. Silva, C. R.; Airoldi, C.; Collins, K. E.; Collins, C. H.; J. Chromatogr., A 2005, 1087, 29.

58. Silva, C. R.; Airoldi, C.; Collins, K. E.; Collins, C. H.; J. Chromatogr., A 2005, 1073, 155 .

59. Lochmüller, C. H.; Marshall, D. B.; Anal. Chim. Acta 1982, 142, 63.

60. Sudo, Y.; J. Chromatogr., A 1996, 737, 139.

61. Pesek, J. J.; Matyska, M. T.; Yu, R. J.; J. Chromatogr., A 2002, 947, 195.

62. Kirkland, J. J.; J. Chromatogr., A 2004, 1060, 9.

63. Naváková, L.; Solich, P.; J. Chromatogr., A 2005, 1088, 24.

64. http://www.chem.agilent.com/en-us/products/consumables/columns/ lcandlcms/zorbaxstablebond80a/pages/default.aspx, acessada em Novembro 2009 e Junho 2010.

65. Kirkland, J. J.; Adams Jr., J. B.; van Straten, M. A.; Claessens, H. A.; Anal. Chem. 1998, 70, 4344.

66. http://www.chem.agilent.com/en-us/products/consumables/columns/ lcandlc-ms/zorbaxextend-c18/pages/default.aspx, acessada em Novembro 2009 e Junho 2010.

67. Neue, U. D.; O'Gara, J. E.; Méndez, A., J. Chromatogr, A 2006, 1127, 161.

68. Németh, T.; Haghedooren, E.; Noszál, B.; Hoogmartens, J.; Adams, E.; J. Chemom. 2008, 22, 178 .

69. Luo, H.; Ma, L.; Paek, C.; Carr, P. W.; J. Chromatogr., A 2008, 1202, 8.

70. Wang, Y.; Harrison, M.; Clark, B. J.; J. Chromatogr., A 2006, 1005, 77.

71. Pellati, F.; Benvenuti, S.; J. Pharm. Biomed. Anal. 2008, 48, 254.

72. Snyder, L. R.; Dolan, J. W.; Carr, P. W.; J. Chromatogr., A 2004, 1060, 77.

73. Rimmer, C. A.; Sander, L. C.; Anal. Bioanal. Chem. 2009, 394, 285.

74. Nomura, A.; Yamada, J.; Tsunoda, K.; Anal. Sci. 1987, 3, 209.

75. Ascah, T. L.; Feibush, B.; J. Chromatogr. 1990, 506, 357.

76. Neue, U. D.; Cheng, Y. F.; Lu, Z.; Alden, B. A.; Iraneta, P. C.; Phoebe, C. H.; van Tran, K.; Chromatographia 2001, 54, 169.

77. Majors, R. E.; LCGC North Am. 2002, 20, 584.

78. Neue, U. D.; O’Gara, J. E.; Méndez, A.; J. Chromatogr., A 2006, 1127, 161.

79. Jing, L. L.; Jiang, R.; Liu, P.; Wang, P. A.; Shi, T. Y.; Sun, X. L.; J. Sep. Sci. 2009, 32, 212.

80. O'Gara, J. E.; Walsh, D. P.; Phoebe Jr., C. H.; Alden, B. A.; Bouvier, E. S. P.; Iraneta, P. C.; Capparella, M.; Walter, T. H.; LCGC North Am. 2001, 19, 632

81. Coyn, J. W.; J. Sep. Sci. 2008, 31, 1712.
82. Silva, R. B.; Silva, C. R.; Airoldi, C.; Collins, C. H.; Jardim, I. C. S. F.; Microchem. J. 2006, 82, 150.

83. Euerby, M. R.; Petersson, P.; Campbell, W.; Roe, W.; J. Chromatogr., A 2007, 1154, 138

84. Horak, J.; Maier, N. M.; Lindner, W.; J. Chromatogr., A 2004, 1045, 43. 85. Neimark, I. E.; Chertov, V. M.; Dokl. Akad. Nauk SSSR 1961, 139, 977.

86. Przybyciel, M.; LCGC North Am. LC Column Technology Supplement 2006, 24, 49.

87. Stevenson, P. G.; Kayllo, S.; Dennis, G. R.; Shalliker, R. A.; J. Liq. Chromatogr. Relat. Technol. 2008, 31, 324.

88. Yang, M.; Fazio, S.; Munch, D.; Drumm, P.; J. Chromatogr., A 2005 , 1097, 124

89. Kayllo, S.; Dennis, G. R.; Shalliker, R. A.; J. Chromatogr., A 2006, 1126, 283.

90. Euerby, M. R.; McKeon, A. P.; Petersson, P.; J. Sep. Sci. 2003, 26, 295.

91. Marchand, D. H.; Croes, K.; Dolan, J. W.; Snyder, L. R.; Henry, R. A.; Kallury, K. M. R.; Waite, S.; Carr, P. W.; J. Chromatogr., A 2005, 1062, 65.

92. Wang, Y.; Harrison, M.; Clark, B. J.; J. Chromatogr., A 2006, 1105, 77.

93. Przybyciel, M.; LCGC North Am. 2005, 23, 554.

94. Berendsen, G. E.; Pikaart, K. A.; Galan, L.; Anal. Chem. 1980, 52, 1990.

95. Zhang, W.; J. Fluorine Chem. 2008, 129, 910.

96. Yamamoto, F. M.; Rokushika, S.; J. Chromatogr., A 2000, 898, 141.

97. Bell, D. S.; Daniel Jones, A.; J. Chromatogr., A 2005, 1073, 99

98. Monde, T.; Kamiusuki, T.; Kuroda, T.; Mikumo, K.; Ohkawa, T.; Fukube, H.; J. Chromatogr., A 1996, 722, 273.

99. Kamiusuki, T.; Monde, T.; Yano, K.; Yoko, T.; Konakahara, T.; Chromatographia 1999, 49, 649.

100. Lanina, S. A.; Toledo, P.; Sampels, S.; Kamal-Eldin, A.; Jastrebova, J. A.; J. Chromatogr., A 2007, 1157, 159.

101. Maldaner, L.; Jardim, I. C. S. F.; J. Sep. Sci. 2010, 33, 174.

102. Bicker, W.; Lämmerhofer, M.; Linder, W.; Anal. Bioanal. Chem. 2008, 390, 263.

103. Gilar, M.; Yu, Y. Q.; Ahn, J.; Fournier, J.; Gebler, J. C.; J. Chromatogr., A 2008, 1191, 162.

104. Li, J.; Shao, S.; Jaworsky, M. S.; Kurtulik, P. T.; J. Chromatogr., A 2008, 1185,185

105. Mclaughlin, L. W.; Chem. Rev. 1989, 89, 309.

106. Venkatramani, C. J.; Zelechonok, Y.; J. Chromatogr., A 2005, 1066, 47.

107. Davies, N. H.; Euerby, M. R.; McCalley, D. V.; J. Chromatogr., A 2007, 1138,65 .

108. Walshe, M.; Kelly, M. T.; Smyth, M. R.; Ritchie, H.; J. Chromatogr., A 1995, 708, 31.

109. Mandell, J. D.; Hershey, A. D.; Anal. Biochem. 1960, 1, 66.

110. http://www.sielc.com/Products_Primesep.html, acessada em Novembro 2009 e Junho 2010.

111. http://www.dionex.com/en-us/products/columns/lc/mixed-mode/lp71735.html, acessada em Novembro 2009 e Junho 2010.

112. Nesterenko, E. P.; Nesterenko, P. N.; Paull, B.; Anal. Chim. Acta 2009, 652,3 .

113. Hemström, P.; Irgum, K.; J. Sep. Sci. 2006, 29, 1784.

114. Ikegami, T.; Tomomatsu, K.; Takubo, H.; Horie, K.; Tanaka, N.; J. Chromatogr., A 2008, 1184, 474.

115. Naidong, W.; J. Chromatogr., B: Anal. Technol. Biomed. Life Sci. 2003, 796, 209.

116. Persson, J.; Hemström, P.; Irgum, K.; J. Sep. Sci. 2008, 31, 1504.

117. Linden, J. C.; Lawhead, C. L.; J. Chromatogr. 1975, 105, 125.

118. Alpert, A. J.; J. Chromatogr. 1990, 499, 177.

119. Olsen, B. A.; J. Chromatogr., A 2001, 913, 113.

120. Guo, Y.; Gaiki, S.; J. Chromatogr., A 2005, 1074, 71.

121. Grumbach, E. S.; Diehl, D. M.; Neue, U. D.; J. Sep. Sci. 2008, 31, 1511. 